\section{A produção de sentidos no jornalismo: da teoria da enunciação à enunciação jornalística}

\section{RESUMO}

Este trabalho tem como objetivo fazer uma discussão teórica do jornalismo não como um simples reprodutor do real, mas como uma atividade que diariamente contribui para a construção social da realidade. Acreditamos que a concepção do jornalismo como um espelho da realidade desconhece a dimensão simbólica da atividade. Nesse sentido, a partir de conceitos da teoria da enunciação procuramos apresentar algumas características da enunciação jornalística tendo como pressuposto que o discurso jornalístico é produzido com base no concurso e do efeito daquilo que the ofertam outros códigos. Isto é, outras vozes e múltiplas polifonias provenientes de outros campos ou deles tomadas por empréstimos.

\section{ABSTRACT}

This article discusses the role of journalism in the construction of our daily "realitiy", calling attention to its symbolic dimension.

PALAVRAS-CHAVE (KEY WORDS)

- Jornalismo (Journalism)

- Enunciação (Enunciation)

- Enunciação jornalística (Journalistic enunciation)

\section{Alfredo Vizeu}

Coordenador do Depto. de Comunicação Social da UFPE

\section{Introdução}

DE UMA MANEIRA geral, sem a preocupação de aprofundarmos o tema, podemos resumir as definições de jornalismo e notícia a partir de dois grandes grupos: os que defendem a notícia como um espelho da realidade e aqueles que concebem a notícia como uma construção social da realidade.

Num estudo clássico sobre a produção da notícia, Tuchman (1983) tendo como pressuposto a concepção sociológica dos atores sociais argumenta que por um lado a sociedade ajuda a formar a consciência e, por outro, mediante uma apreensão intencional dos fenômenos do mundo social compartilhado - mediante seu trabalho efetivo -, os homens e as mulheres constroem e constituem os fenômenos sociais coletivamente. Segundo a autora, cada uma destas perspectivas ao atuar sobre os atores sociais determina uma abordagem diferente da notícia.

A idéia da notícia como um espelho da realidade corresponderia à concepção tradicional das notícias. Este ponto de vista defende a "objetividade" como um elemento-chave da atividade jornalística. Dentro desta concepção, o máximo que se admite é a possibilidade de que as notícias reflitam o ponto de vista do jornalista (Stamm, 1976).

Já Gaye Tuchman defende que a notícia não espelha a realidade. Para a autora, a notícia ajuda a constituí-la 
como um fenômeno social compartilhado, uma vez que no processo de definir um acontecimento a notícia define e dá forma a este acontecimento. Ou seja, a notícia está permanentemente definindo e redefinindo, constituindo e reconstituindo fenômenos sociais.

Entendemos que a construção da notícia não se reduz a uma mera técnica, a simples mobilização de regras e normas fornecidas pelos manuais de redação ou aprendidas no desempenho da atividade profissional. Acreditamos que tal ponto de vista desconhece a dimensão simbólica do trabalho jornalístico.

Consideramos que é no trabalho da enunciação que os jornalistas produzem discursos. E é no interior do próprio processo discursivo, por meio de múltiplas operações articuladas pelos processos da própria linguagem, que a audiência é construída antecipadamente.

Por isso, antes de entrarmos na enunciação jornalística propriamente dita, procuramos contextualizar a questão da enunciação, que ponderamos importante para tratar da enunciação no jornalismo. Partimos do princípio que a teoria da enunciação teve como precursor Bakhtin e ganhou um impulso na França com a obra do lingüista Benveniste, que propôs estudar a subjetividade na língua: o aparelho formal da enunciação.

Acompanhamos Bakhtin (1992) quando concebe a língua como um produto sócio-histórico, como forma de interação social realizada por meio de enunciações. O conceito da língua como interação social desempenhou um papel importante nos estudos que, hoje, se desenvolvem sobre a interação verbal, como a pragmática, a teoria da enunciação e a análise do discurso que tem como princípio que a linguagem é ação e não um mero instrumento de comunicação.

Bakhtin chama a atenção para o fato de que a verdadeira substância da língua não é constituída por um sistema abstrato de formas lingüísticas, nem pela enunciação monológica isolada, nem pelo ato psicofisiológico de sua produção, mas pelo fenômeno social da interação verbal, realizada através da enunciação ou das enunciações: "A interação verbal constitui, assim, a realidade fundamental da língua" (Bakhtin, 1992, p. 123). Como lembra o autor, a enunciação é de natureza social.

Ele argumenta que toda palavra comporta duas faces, sendo determinada tanto pelo fato de que procede de alguém como pelo fato de que se dirige para alguém. Nesse sentido, constitui justamente o produto da interação do locutor e do ouvinte, isto é, toda palavra serve de expressão de um em relação ao outro.

Bakhtin instaura o dialogismo como princípio constitutivo da linguagem e condição de sentido do discurso: "A língua constitui um processo de evolução ininterrupto, que se realiza através da interação verbal dos locutores" (1992, p. 127).

O outro está sempre presente nas formulações do autor e tem tanto a função de quem recebe como também de quem permite ao locutor perceber o seu próprio enunciado:

"Os outros, para os quais o meu pensamento se torna, pela primeira vez, um pensamento real (e, com isso, real para mim), não são ouvintes passivos, mas participantes ativos da comunicação verbal. Logo de início, o locutor espera deles uma resposta, uma compreensão responsiva ativa. Todo o enunciado se elabora como para ir ao encontro dessa resposta. $O$ índice substancial (constitutivo) do enunciado é o fato de dirigir-se a alguém de estar voltado para o destinatário" (Id., 2000, p. 320).

Dessa forma, o interlocutor é constitutivo do próprio ato de produção da linguagem, de certa maneira ele é co-enunciador do texto e não um mero decodificador de mensagens. Ele 
desempenha um papel fundamental na constituição do significado e na produção. Logo, um enunciado deve ser analisado levando-se em conta sua orientação para o outro.

Outra noção introduzida por Bakhtin (1981, p. 65-85) foi o conceito de polifonia, resultado dos trabalhos desenvolvidos sobre a natureza do discurso literário. Ao analisar a obra de Dostoievski e uma série de textos da literatura popular, Bakhtin percebe que o autor investe suas personagens de uma série de máscaras diferentes. Como essas máscaras representam várias vozes a falarem simultaneamente sem que uma dentre elas seja preponderante, Bakhtin qualifica o texto de Dostoievski de polifônico.

\section{O aparelho formal da enunciação}

O conceito bakhtiniano de língua como interação social reintroduz, nos estudos da linguagem, a reflexão sobre a noção de sujeito. Deixa-se de lado o conceito de língua como um sistema neutro e passa-se a ver a língua como o lugar privilegiado de manifestações enunciativas. Tal proposição apresenta-se claramente na teoria da enunciação de Benveniste.

Como mostrou Benveniste, o único modo de fazer o discurso funcionar é pela intervenção do sujeito, que nele investe sua subjetividade: "A enunciação é este colocar em funcionamento a língua por um ato individual de utilização" (1989, p. 82).

No entanto, no ato enunciativo, o sujeito não constitui apenas a si, sujeito locutor, mas também o sujeito-alocutário, isto é, define não só a posição eu, mas também a do tu: "...ele implanta o outro diante de si, qualquer que seja o grau de presença que ele atribua a este outro. Toda a enunciação é, explicita ou implicitamente, uma alocução, ela postula um alocutário" (lbid., p. 84).

Para o autor, o que, em geral, caracteriza a enunciação é a acentuação da relação discursiva com o parceiro. $\mathrm{Na}$ realização do seu estudo sobre o aparelho formal da enunciação, ele tomou como os principais pontos de partida os sistemas pronominal e verbal do francês (Id., 1995, p. 247-283).

$\mathrm{Na}$ descrição do sistema pronominal, o autor distingue os pronomes da pessoa $\left(1^{\mathrm{a}}\right.$ e $\left.2^{\mathrm{a}}\right)$ dos pronomes da não-pessoa $\left(3^{\mathrm{a}}\right)$. Os primeiros designam os interlocutores, os sujeitos envolvidos na interlocução (eu, tu, você; nós, vós, vocês); os últimos designam os referentes (seres do mundo extralingüístico de que se fala) e, assim, não devem ser colocados na mesma classe dos primeiros.

Quanto ao sistema verbal, Benveniste diz que existem dois planos de enunciação: o discurso e a história, cada um com os seus tempos característicos. Na história, tem-se o relato de eventos passados, sem o envolvimento do locutor, como se os fatos narrassem a si mesmos.

Pertencem à ordem da história o passé simple (pretérito perfeito simples), os pronomes da não-pessoa, o imperfeito, o mais-que-perfeito e o futuro do pretérito do indicativo. Já o discurso é de ordem diversa: num determinado momento, em determinado lugar, um indivíduo se apropria da língua, instaurando-se como eu, e, ao mesmo tempo, instaurando o outro como tu. É uma enunciação que pressupõe um locutor e um ouvinte e, no primeiro, a intenção de influenciar o outro de alguma maneira.

Orlandi (1996) critica a concepção de sujeito de Benveniste como ser único, central, origem e fonte do sentido. Ducrot (1987) define a enunciação independentemente do autor da palavra como o acontecimento constituído pela aparição do enunciado.

Mainguenau (1997, p. 40) faz algumas restrições ao uso da enunciação na análise do discurso: a) não deve ser concebida como a apropriação do sistema da língua por parte de um indivíduo, o sujeito só chega à enunciação através de múltiplas 
regras do gênero de discurso; b) não reside num único enunciador, é a interação que está em primeiro lugar; c) o indivíduo que fala não é necessariamente a instância que se encarrega da enunciação.

Apesar das ressalvas, Mainguenau admite que a enunciação trouxe contribuições. Para o autor, um dos contributos fundamentais foi o de colocar em evidência a dimensão reflexiva da atividade lingüística: o enunciado só remete para o mundo, seu referente, quando reflete $o$ ato da enunciação que o produz.

Desse modo, as pessoas e o tempo do enunciado são referenciados relativamente a essa situação de enunciação; assim, o enunciado possui o valor elocutório que ele mostra através da sua enunciação.

Em seu livro Quando Dizer é Fazer, Austin (1990) distingue, com precisão, três atividades complementares na enunciação. Proferir um enunciado é ao mesmo tempo:

a) realizar um ato locutório, produzir uma série de sons dotada de um sentido numa língua;

b) realizar um ato ilocutório, produzir um enunciado ao qual se vincula convencionalmente através do próprio dizer uma força;

c) realizar uma ação perlocutória, isto é, provocar efeitos por intermédio da palavra (por exemplo, pode-se fazer uma pergunta

d) ato ilocutório - para interromper alguém, para embaraçá-lo, para mostrar que se está ali, etc.). O campo do perlocutório sai do contexto propriamente lingüístico.

Grosso modo, Austin mostra que é impossível encontrar enunciações sem valor performativo que só descrevessem o mundo. Até um enunciado que parece puramente descritivo, como está chovendo, coloca-nos diante de uma realidade nova, realiza também uma ação, no caso, um ato de afirmação.
Para Austin, entre está chovendo e afirmo que está chovendo haveria apenas uma diferença de explicitação; o performativo seria explícito no segundo caso e primário no primeiro. Decerto ações como sustentar, afirmar, ordenar... são verbais; não são do mesmo tipo do que ações institucionais como jurar, batizar ou decretar, mas trata-se, nos dois casos, de atos de linguagem. No telejornalismo, é muito comum os editores trabalharem com atos ilocutórios ao interpelar a audiência. Por exemplo: Confira...

Para uma concepção da linguagem ingênua, os enunciados são, de certo modo, transparentes; devem se apagar diante do estado de coisas que representam. Em compensação, na perspectiva pragmática, um enunciado só consegue representar um estado de coisas distinto dele se mostrar também a sua própria enunciação.

Dizer algo parece inseparável do gesto que consiste em mostrar que se diz. Isso se manifesta através dos embreantes; qualquer enunciado tem marcas da pessoa e do tempo que refletem sua enunciação, coloca-se mostrando o ato que o faz surgir.

A enunciação constitui a âncora da relação entre a língua e o mundo: ela permite representar os fatos no enunciado, constituindo, ela própria, um fato, um acontecimento único definido no tempo e no espaço.

A isso, acrescentaríamos que, a partir dos estudos da enunciação, se passou a estudar outras marcas da presença do enunciador, do co-enunciador, nos enunciados produzidos, como, por exemplo, os indicadores de modalidade, todos os tipos de modalizadores ou marcas lingüísticas.

\section{Jornalismo e a construção do real}

É no trabalho da enunciação, na operação sobre vários discursos, que os jornalistas produzem as notícias. No entanto, nessa operação, os profissionais não são simples 
reprodutores do real e senhores soberanos dos discursos, como reza toda uma tradição do fazer jornalístico.

Fausto Neto (1991, p. 25-40) denuncia essa falácia que situa o jornalismo num contexto de desobrigações, no qual funciona como dispositivo intermediário, instrumento, articulador e suporte de algo que lhe é externo.

O autor lembra que a enunciação é uma espécie de tomada de posição, a instância que estrutura o valor do dito. Nesse sentido, o sujeito enunciador não constitui um todo unificado. Isso porque, se é verdade que a língua é finita na definição dos seus limites e de suas regras; por outro lado, também é verdade que são infinitas as possibilidades modalizadoras de uso da língua, pela mediação da palavra, pelo sujeito.

Sem dúvida, o enunciador está presente no discurso através de suas marcas. No entanto, ele não tem controle, a priori, do que deve ser dito de uma maneira melhor ou não. É neste trabalho de enunciação-apropriação da língua onde se dá o modo pelo qual o jornalista (enunciador da informação) se relaciona com o que ele mesmo diz, isto é, está relacionado com o problema de como ele legitima o seu discurso ou o torna aceitável. Mas isso não implica um controle do discurso voluntariamente definido pelo sujeito.

O trabalho jornalístico é concebido sempre a partir de mensagens que ganham forma de matérias segundo economias específicas a cada sistema e/ou veículo de comunicação, que produzem dimensões classificatórias da realidade.

Compartilhamos da opinião de Fausto Neto para quem toda notícia se constitui uma espécie de formação substitutiva. Ou seja, é algo que tenta se colocar no lugar de outra coisa que lhe é exterior. Sendo assim, o dito tem uma objetivação expressa em forma de matéria significante (mensagem).

Um conjunto de operações é estruturado, anteriormente, por diferentes instâncias, de certa forma, como um pré-requisito à emergência do dito. Como o tempo do fato bruto, por exemplo, o incêndio em uma fábrica, e o tempo da produção da matéria se constituem num outro, não é possível a superposição de ambos, restando apenas o recurso do jornalista (o enunciador) recorrer à mediação dos procedimentos de linguagem para procurar reconstituir 0 tempo do fato bruto.

Esse é um dos motivos pelos quais a maioria dos autores que estudam o jornalismo denomina-o de discurso da atualidade. Como afirma Gomis (1991), o presente é mais direto e próximo. É o tempo do imediato, do vivido.

Outra razão apontada pelo autor para o uso do presente é por tratar-se do tempo do cotidiano. Quando as pessoas querem contar alguma coisa que ocorreu com elas ou Ihes chamou a atenção, a tendência é contar no presente.

Os jornais, os radiojornais e os telejornais mediam o passado e o futuro convertendo todos os tempos no presente, convidando-nos a atuar nesse tempo difuso, imaginado como um presente aberto ao que está por vir.

"O presente é o que se comenta. Por isso são mais notícias as que duram mais tempo porque são elas que dão consistência a nosso presente de referência, ao nosso presente coletivo, comum, aos fatos que comentamos socialmente." (Ibid., p. 34)

Por isso, busca-se, por conta do papel que desempenham as técnicas discursivas e os seus efeitos junto à audiência, legitimar o tempo e o modo discursivo como o próprio tempo do fato. Como o processo de interação social vive dos protocolos de linguagem, é de se supor, igualmente, que a veracidade e a legitimidade dos fatos estejam, portanto, no reino dos discursos.

"A isto estamos chamando modos/ 
maneiras de dizer. Se nos é impossível aprisionar o tempo do 'fato bruto', estruturamos nossa compreensão pelos processos de classificação e inteli-gibilidade social definidos pelas operações discursivas da comunicação social. Neste sentido, sim, o discurso jornalístico produz fatos." (FAUSTO NETO, 1991, p. 30, o itálico é nosso)

No jornalismo, a linguagem não é apenas um campo de ação, mas a sua dimensão constitutiva. É a condição pela qual o sujeito constrói um real, um real midiatizado.

Nesse sentido, a enunciação jornalística é bastante singular em função de esse campo deslocar-se sempre como um lugar que retrata e cria o lugar do outro, a partir de leis e regras determinadas.

"A enunciação jornalística se faz a partir de uma dupla falta. A primeira àquela relativa ao próprio 'estatuto' do sujeito, face à ordem simbólica, que toma a palavra como representante da coisa. A segunda, por se constituir num discurso relatador, o saber jornalístico tenta superar esta impossibilidade de ser um discurso de 'primeira mão' através das multiplici-dades de investimentos enunciativos (lingüísticos, discursivos, pedagógicos, etc.), para, através de modalidades substitutivas, dar conta de um certo real." (Ibid., 1991, p. 31)

Dessa forma, o discurso jornalístico é produzido com base no concurso e do efeito daquilo que lhe ofertam outros códigos, isto é, outras vozes e múltiplas polifonias provenientes de outros campos culturais ou que deles são tomadas por empréstimo: vozes deontológicas - que dão conta de um certo fazer discursivo; as vozes da divisão social do trabalho inerente ao jornalismo; as vozes da pedagogia - cada vez mais o discurso jornalístico se insinua como uma espécie de saber explicativo dos processos sociais.

Também não podemos deixar de lado as vozes internas do próprio discurso jornalístico. São as técnicas que mobilizam as regras de vários campos: convenções audiovisuais, vocabulário, normas gramaticais, procedimentos profissionais, estilo, entre outros, para a produção das notícias.

Entendemos que o processo de enunciação jornalística é regulamentado através de procedimentos mais generalizados e que se encontram estabelecidos em espécies de macrocódigos: a língua, as matrizes culturais, as regras sociais, a ética e as ideologias. E, por microcódigos, como os códigos particulares estabelecidos pelas empresas de comunicação, por exemplo, os manuais de redação, mas também os valores-notícia (critérios de noticiabilidade), que vão ser manejados e mobilizados no processo de enunciação.

A dependência das fontes de informação e de opinião reduz o grau de autonomia do jornalista como autor de um texto e faz com que o discurso jornalístico seja marcado pela intercalação entre discurso narrativo e discurso citado (fragmentos da fala), na acepção de Bakhtin, que vê o discurso indireto como a transmissão analítica do discurso de outrem.

"O emprego do discurso indireto ou de uma de suas variantes implica uma análise da enunciação simultânea ao ato de transposição e insepa-rável dele. A tendência analítica do discurso indireto manifesta-se principalmente pelo fato de que o elemento emocional e afetivo do discurso não é literalmente transposto ao discurso indireto, na medida em que não são expressos no conteúdo mas nas formas de enunciação." (BAKHTIN, 1992, p. 158-159)

Bakhtin (1992, p. 161) explica que 
a análise envolvida na construção de um discurso indireto pode partir de duas abordagens:

I - Discurso indireto analisador do conteúdo

- quando a enunciação de outrem é apreendida como a tomada de posição com conteúdo semântico preciso, o que leva à recomposição do sentido exato do que disse o falante (ou locutor). Tal apreensão é feita no plano meramente temático $e$ permanece surda e indiferente a tudo que não tenha significação temática.

"A variante analisadora do conteúdo abre grandes possibilidades às tendências à réplica e ao comentário no contexto narrativo, ao mesmo tempo em que conserva uma distância nítida e estrita entre as palavras do narrador e as palavras citadas." (Ibid., 1992, p. 161)

Esse tipo de transmissão preserva a integridade e a autonomia da enunciação original, mais em termos semânticos do que sintáticos, mas gera uma certa despersonalização do discurso citado. Nessa variante, "a propriedade do falante só existe enquanto ocupa uma posição semântica determinada (cognitiva, ética, moral, de forma de vida)" (Ibid., 1992, p.164), e transmitida de forma estritamente objetiva.

II - Discurso indireto analisador da expressão - quando a enunciação de outrem é apreendida e transmitida como uma expressão própria do locutor, não só em relação ao objeto ou o assunto sobre o qual fala, mas também - e principalmente - por sua maneira individual ou tipológica de se expressar (por exemplo: dificuldades de falar fluentemente, sotaques, jargões ou gestos característicos, etc.) Implica, necessariamente, juízo de valor do narrador sobre o modo de pensar, falar e se comportar do seu interlocutor. Essa variante - pouco explorada no jornalismo - integra ao discurso indireto palavras e maneiras de se expressar de outrem de tal forma que sua especificidade, sua subjetividade, seu caráter típico são claramente percebidos.

Entre a variante analisadora de conteúdo e a analisadora de expressão, Bakhtin situa a variante impressionista, que busca transmitir o discurso interior - pensamentos e sentimentos dos personagens ou a registrar impressões subjetivas sobre o comportamento de alguém. Esse recurso é muito encontrado nas reportagens de comportamento em televisão.

As características da enunciação jornalística

$\mathrm{Na}$ enunciação jornalística, o jornalista dá conta daquilo que aconteceu recentemente e, por esse motivo, daquilo que ainda não acedeu à memória coletiva e que poderá ir gravar-se nela, em primeira mão, precisamente pelo fato de o jornalista enunciar (RODRIGUES, 1996).

A seleção dos acontecimentos que o jornalista enuncia pressupõe, da sua parte, um julgamento, na maior parte dos casos implícito, acerca da relevância e do seu interesse para o público. A formação desse julgamento está relacionada implicitamente a uma visão do mundo interiorizada pelo próprio jornalista que a considera, também, universalmente partilhada pela audiência.

O jornalista, ao enunciar, parte do pressuposto de que a audiência tem interesse em conhecer o que enuncia. Isto é, a enunciação jornalística, nesse sentido, é um trabalho de transformação incorporal dos fatos, fazendo-os aceder, através da sua enunciação, ao público.

Um texto jornalístico é, por isso, um ato de linguagem que consiste no desdobramento de um trabalho de transformação, feliz ou infeliz, provocado pelas ações que a enunciação põe em cena, colocando, assim, em relação duas temporalidades-limite, um antes e um 
depois, mediante uma temporalidade transformadora de mediação.

Como tal, o texto jornalístico é um processo de doação de sentido, uma vez que dá a ler uma orientação para o devir, é discurso, disposição ordenadora dos fatos, tornando-os, desse modo, inteligíveis, situados numa lógica racionalmente compreensível.

Nessa perspectiva, na enunciação jornalística, predomina o valor referencial; pressupõe a veracidade dos fatos a que se refere e a autenticidade do seu relato. O pressuposto dessa veracidade institui um autêntico contrato entre o jornalista, por um lado, e a audiência, por outro.

Uma das questões interessantes a colocar da enunciação jornalística é a da sua inteligibilidade por parte da audiência: como é possível que os enunciados elaborados pelos jornalistas sejam entendidos por um número indefinido de pessoas, apreendendo o seu sentido a partir da experiência de mundos vividos e situados dentro de horizontes heterogêneos?

O jornalista pode recorrer aos processos metalingüísticos, de redundância e contextualização, para se fazer compreendido. Mas não tem, ao seu alcance, a heterogeneidade de sentidos a que seu discurso dá origem, já que não pode identificar todos e cada um dos seus interlocutores, nem pode, conseqüentemente, no decurso do processo enunciativo, controlar as hipóteses interpretativas a partir das quais cada um infere aquilo que pretende dizer.

Ele transmite um conjunto de saberes, converte, em notícia, os fatos ocorridos no mundo, informa sua audiência daquilo que de relevante aconteceu, mas não controla a heterogeneidade de sentidos que essas transmissões e esses saberes adquirem por parte dos seus interlocutores, não Ihes comunica um sentido, não integra esses sentidos num mundo mutuamente partilhado.

Por exemplo, há uma diferença muito grande entre ser informado da ocorrência de um acidente de carro e ser informado pelo vizinho de que o gato dele foi atropelado em frente à sua porta.

É claro que as mensagens jornalísticas que digam respeito ao mundo mutuamente partilhado pelo jornalista e pela audiência podem adquirir uma dimensão comunicacional. Mas nem essa dimensão é partilhada pela totalidade da audiência da informação, nem é ela que constitui e justifica o seu valor propriamente informativo.

A enunciação jornalística, ao autonomizar os fatos, as ações e as palavras do mundo vivido do seu acontecimento, liberta-os de sentido tradicionais, da sua carga corporal concreta, tornando-os, assim, disponíveis para toda espécie de novos sentidos e de novos investimentos simbólicos. Desse modo, cada indivíduo que integra a audiência, ao interpretar os novos saberes do discurso jornalístico, a partir do seu próprio mundo vivido, pode constituir-se num sujeito autônomo de constituição de sentido.

Há ainda uma outra modalidade a ser levada em conta na enunciação jornalística: o silêncio. É um silêncio que não cessa de se deslocar, à medida que o jornalismo prossegue incansavelmente a sua representação discursiva. Embora logicamente prévio, o silêncio percorre, no entanto, de uma ponta à outra, todo o discurso jornalístico.

Mesmo quando o discurso jornalístico é referencialmente correto, quando representa exatamente aquilo que aconteceu, é atravessado por uma diferença insanável entre, por um lado, aquilo que, numa primeira aproximação, podemos designar como a dimensão referencial e a dimensão significante e, por outro lado, a dimensão expressiva e o sentido da representação discursiva.

É nos interstícios entre essas diferentes dimensões da enunciação que um silêncio constitutivo e indizível, mas 
cheio de sentidos heterogêneos, se instala. É, no fundo, com esse silêncio que o discurso jornalístico dialoga.

Mas, além dessas modalidades constitutivas da enunciação jornalística, há ainda outras categorias de silêncio que atravessam as suas formas de expressão, tais como elipses e reticências. Muito mais fáceis de identificar, essas modalidades de silêncio deixam em branco unidades significantes, na cadeia de expressões lingüísticas, unidades que a audiência é levada a complementar, assumindo, assim, um papel ativo, tanto na reconstituição da cadeia das formas significantes elidida ou implicitada como na elaboração de um sentido comum.

As formas da enunciação jornalística são marcadas por processos de raciocínio ou cadeias de razões que visam a determinados efeitos de reconhecimento (apreensão, compreensão pela audiência) e podem restringir-se ao anúncio, à descrição, à argumentação, à demonstração e à persuasão.

I - Anunciar - dizer o que aconteceu ou vai acontecer; dizer o que alguém disse, subtendendo a relevância do dito;

II - Descrever- relatar as etapas de um fato, com suas circunstâncias; os passos de um personagem, com seus comportamentos, atitudes, declarações ou proposições, ou o quadro de uma situação, com os diversos aspectos envolvidos;

III - Demonstrar - provar a relevância, validade ou veracidade do que foi anunciado ou descrito;

IV- Argumentar - orientar inferências a partir do que foi dito ou realizado (é o que acontece, comumente, na abertura das matérias no telejornalismo);

V- Persuadir - buscar convencer o outro da importância e da veracidade do relato, utilizando-se, no caso da sedução, de apelos muito comuns (por exemplo, na abertura a cabeça de uma matéria dizendo: Violência na zona norte de Vitória).

Para Lopes (1990), independente do tipo de notícia ou reportagem, os textos jornalísticos podem mobilizar diferentes formas de enunciação e de organização dos enunciados. Entendemos que isso vai depender da intenção comunicativa, do repertório informativo, cultural e lingüístico da audiência, da flexibilidade das normas de redação de cada veículo.

É nesse processo que a recepção é construída, mediante um conjunto de regras e de instruções construídas pelo campo da produção, para serem seguidas pelo campo da recepção (audiência), condição por meio do qual ele se insere no sistema interativo proposto e pelo qual ele é reconhecido e, conseqüentemente, se reconhece como tal.

A recepção não pode ser definida apenas pelos estudos que as estratégias de marketing propõem para ajudar as empresas jornalísticas a construir o mercado. É claro que traços e características sociais identificados pelos institutos de pesquisa orientam as organizações a construírem o mercado e um perfil da audiência.

Entretanto, entendemos que a recepção é construída na própria economia enunciativa:

“...tais vínculos são construídos no interior da própria discursividade, bem como daquelas leis que ao nível do discurso tratam de tipificar não só as maneiras pelas quais o suporte constrói as notícias, mas especialmente a organização mesma da sua noção de leitor." (Fausto Neto, 1991, p. 37)

O outro, que compôs a cadeia interativa da atividade linguageira jornalística, não é apenas um personagem revestido com certos matizes de indicadores sociais, mas alguém que é construído na própria 
produção imaginária dos organizadores e enunciadores do discurso.

Nesse sentido, acreditamos que fica difícil pensar o jornalismo como uma mera reprodução do real. Como podemos ver são tantos os "discursos" - não cometeríamos uma heresia se disséssemos que são infinitos - que atravessam 0 campo jornalístico, são tantas as tensões, as "vozes", as práticas discursivas, que o reduzir a uma simples técnica, ao simples acionamento de regras "mecânicas", seria perder sua própria dimensão, seu próprio objeto .

\section{Referências}

AUSTIN, J. L. Quando dizer é fazer: palavras e ação. Porto Alegre: Artes Médicas, 1990.

BAKHTIN, M. Estética da criação verbal. $3^{a}$ ed. São Paulo: Martins Fontes, 2000.

Marxismo e filosofia da linguagem. $6^{a}$ ed. São Paulo: HUCITEC, 1992.

Problemas da poética de Dostoievski. Rio de Janeiro: Forense-Universitária, 1981.

BENVENISTE, E. Problemas de lingüística geral I. $4^{\mathrm{a}}$ ed. Campinas: Pontes/Editora da Unicamp. 1995. 1989.

Problemas de lingüística geral II. Campinas: Pontes,

DUCROT, 0.0 dizer e 0 dito. Campinas: Pontes, 1987.

FAUSTO NETO, A. Mortes em derrapagem: os casos Corona e Cazuza no discurso da comunicação de massa. Rio de Janeiro: Rio Fundo, 1991.

GOMIS, L. Teoría del periodismo: cómo se forma el presente. México: Paidós, 1991.

LOPES, S. A . Sobre o discurso jornalístico: verdade, legitimidade e identidade. Rio de Janeiro: UFRJ/ECO, 1990. Dissertação (Mestrado em Comunicação Social).
MAINGUENAU, D. Novas tendências em análise do discurso. $3^{2}$ ed. Campinas: Pontes/Editora da Unicamp, 1997.

ORLANDI, E. P. A linguagem e seu funcionamento: as formas do discurso. Campinas: Pontes, 1996.

RODRIGUES, A. D. 0 discurso mediático. Lisboa, 1996, mimeo.

STAMM, K.R. "The nature of news-news concepts". In: McCOMBS, Maxwell; SHAW, Donald Lewis; GREY, David (orgs.). Handbook of reporting methods. Houtghton Mifflin Company: Londres, 1976.

TUCHMAN, Gaye. La producción de la noticia: estudio sobre la construcción de la realidade. Barcelona: Bosch, 1993. 